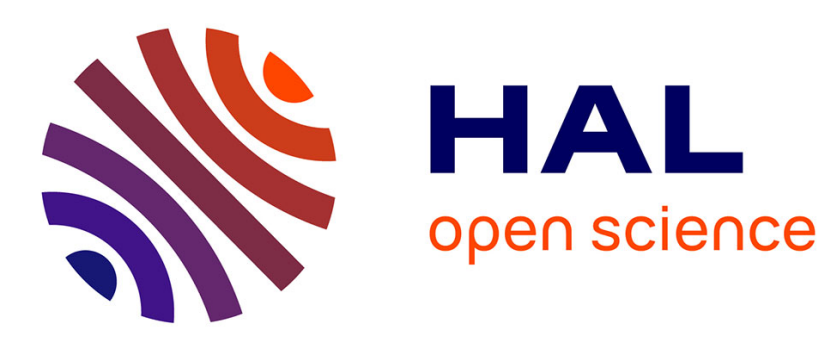

\title{
Shear wave attenuation in smectic-A liquid crystals
}

F. Kiry, P. Martinoty

\section{To cite this version:}

F. Kiry, P. Martinoty. Shear wave attenuation in smectic-A liquid crystals. Journal de Physique Lettres, 1977, 38 (19), pp.389-392. 10.1051/jphyslet:019770038019038900 . jpa-00231403

\section{HAL Id: jpa-00231403 https://hal.science/jpa-00231403}

Submitted on 1 Jan 1977

HAL is a multi-disciplinary open access archive for the deposit and dissemination of scientific research documents, whether they are published or not. The documents may come from teaching and research institutions in France or abroad, or from public or private research centers.
L'archive ouverte pluridisciplinaire HAL, est destinée au dépôt et à la diffusion de documents scientifiques de niveau recherche, publiés ou non, émanant des établissements d'enseignement et de recherche français ou étrangers, des laboratoires publics ou privés. 


\author{
Classification \\ Physics Abstracts \\ $61.30-62.60-62.80$
}

\title{
SHEAR WAVE ATTENUATION IN SMECTIC-A LIQUID CRYSTALS (*)
}

\author{
F. KIRY and P. MARTINOTY
}

\author{
Laboratoire d'Acoustique Moléculaire (E.R.A. au C.N.R.S.), Université Louis-Pasteur, \\ 4, rue Blaise-Pascal, Strasbourg, France
}

(Reçu le $1^{\text {er }}$ juillet 1977, révisé le $1^{\text {er }}$ septembre 1977, accepté le 6 septembre 1977)

\begin{abstract}
Résumé. - Nous avons étudié le comportement de deux smectiques-A soumis à une contrainte de cisaillement ultrasonore dans le cas où le vecteur d'onde est parallèle à la normale aux couches. Nous avons mis en évidence un processus de relaxation que nous discutons en supposant l'existence d'un couplage entre les fluctuations du directeur et l'écoulement local.
\end{abstract}

\begin{abstract}
We have studied the shear impedance of two smectics-A when the propagation of the shear wave is along the normal to the layers. We observed that the real part and the imaginary part of the shear impedance differ significantly, indicating a relaxation process. We analysed our results on the basis of a coupling between the director fluctuations and the shear flow.
\end{abstract}

Impedance methods are traditionally used to study the shear properties of liquids. An indication of a relaxation process is given when the imaginary part $X$ is not equal to the real part $R$ of the shear mechanical impedance, a quantity which is defined as the negative ratio of shear stress to the rate of change of shear displacement.

Using the so-called impedometer method [1] we have recently studied at ultrasonic frequencies the shear impedance of a liquid crystal which has only nematic [2] and isotropic [3] liquid phases. In the isotropic phase we observed the relaxation process predicted by de Gennes [4]. In the nematic phase we found $R \simeq X$ giving no indication of relaxation. This last result enabled us to deduce three effective viscosity coefficients of the nematic.

In this paper we are dealing with smectic-A phases and we present evidence of a relaxation effect when the propagation of the shear wave is along the normal to the layers [5].

The determination of the shear impedance is obtained from measurements of the reflection coefficient of a shear wave at the solid-liquid interface between a fused-quartz bar and a smectic liquid crystal. Oblique and normal incidence can be used, the

(*) Work supported by the D.G.R.S.T. under contract 7470458 . result being basically identical for both cases [6-7]. We used oblique incidence because the sensitivity of the method is increased by reflecting the shear wave from the interface at large angles of incidence [8]. Our experimental set-up has been described in detail previously [2]. The homeotropic alignment was obtained by coating the reflecting surface of the bar and the cover glass with a layer of lecithin. The layer was so thin that it did not detectably affect the received pulses. The orientation was examined in polarized light between crossed polarizers. A schematic diagram of the experiment is shown in figure 1 .

Diheptylazoxybenzene has two mesomorphic phases, smectic A from $34^{\circ}$ to $54^{\circ} \mathrm{C}$ and nematic from $54^{\circ}$ to $71^{\circ} \mathrm{C}$. It is known to have a nearly-second-order nematic to smectic A phase transition. Our measurements of $R$ and $X$ at $15 \mathrm{MHz}$ are reported in figure 2 . In the smectic-A phase we observe that $R$ and $X$ are quite different indicating a relaxation process. In the

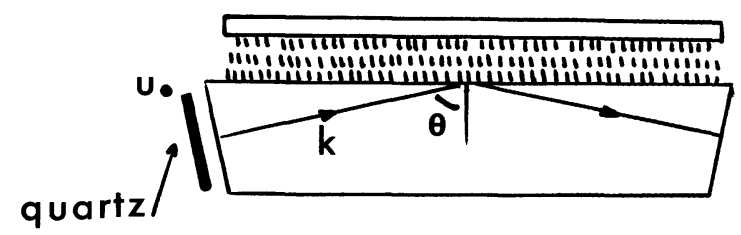

FiG. 1. - Schematic diagram of the acoustic system : the vibration $u$ is parallel to the reflecting surface. $k$ is the wave vector. 


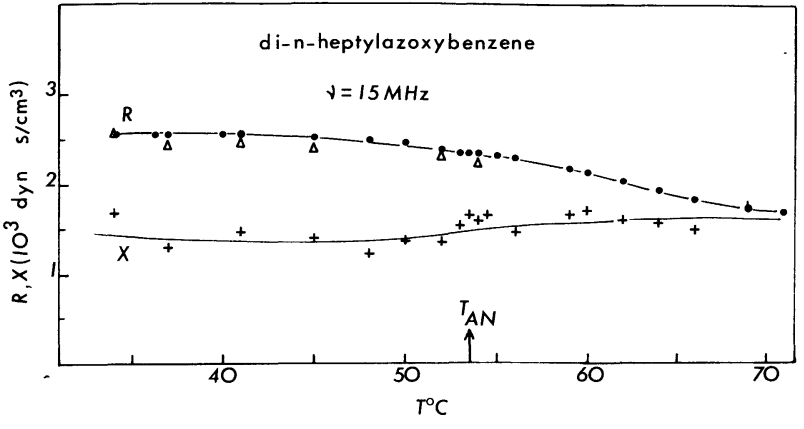

FIG. 2. - The real $R$ and imaginary $X$ parts of the shear impedance in the nematic and smectic-A phases of di-n-heptylazoxybenzene. The symbols $\triangle$ and $\Delta$ are for two different samples.

nematic phase there is also evidence of a relaxation process which becomes more and more apparent as the phase transition is approached. Similar behaviour was observed at $25 \mathrm{MHz}$.

Since the transition is of second order we expect to observe critical viscosities which show a relaxation behaviour at finite frequencies [9]. In fact it has been predicted that the viscosity $\eta_{3}$ (in the MPP notation [10]) which is measured here is not critical. This was verified by capillary [11] and light scattering measurements [12].

a) The smectic phase. - The simplest model to explain these results is to assume that the director is disturbed from its equilibrium value by the shear stress (of angular frequency $\omega$ ) and relaxes with a single characteristic time $\tau$ [13]. A simple form for the relaxation behaviour of the viscosity $\eta_{3}$ is given by :

$$
\eta_{3}(\omega)=\eta_{3}^{0}-\delta \eta_{3} \frac{i \omega \tau}{1+i \omega \tau}
$$

$\eta_{3}$ goes from $\eta_{3}^{0}($ for $\omega \tau \ll 1)$ to $\eta_{3}^{0}-\delta \eta_{3}($ for $\omega \tau \gg 1)$. The relaxation time $\tau$ is given by

$$
\tau^{-1}=\frac{B_{\perp}}{\gamma}
$$

where $B_{\perp}$ is the force maintaining the molecules normal to the layers and $\gamma$ is a viscosity coefficient ;

$\tau^{-1}$ is expected to vanish when the A-N transition is second order [14].

The real and imaginary parts of the viscosity $\eta_{3}$ are given by

$$
\begin{aligned}
& \eta_{3}^{\prime}(\omega)=\eta_{3}^{0}-\delta \eta_{3} \frac{\omega^{2} \tau^{2}}{1+\omega^{2} \tau^{2}} \\
& \eta_{3}^{\prime \prime}(\omega)=\delta \eta_{3} \frac{\omega \tau}{1+\omega^{2} \tau^{2}} .
\end{aligned}
$$

Since the viscosity is a complex number the liquid crystal presents an apparent rigidity coefficient $G^{\prime}$ given by :

$$
G^{\prime}(\omega)=\omega \eta_{3}^{\prime \prime}(\omega)
$$

From our measurements we computed the shear modulus $G^{\prime}$ and the real part $\eta_{3}^{\prime}$ of the viscosity using the formulae :

$$
\eta_{3}^{\prime}=\frac{2 R X}{\rho \omega}, \quad G^{\prime}=\frac{R^{2}-X^{2}}{\rho}
$$

where $\rho$ is the density. In what follows we have assumed $\rho=1$.

The variations of $\eta_{3}^{\prime}$ and $G^{\prime}$ with temperature are shown in figure 3 . We observe that

$$
G^{\prime}(25 \mathrm{MHz})>G^{\prime}(15 \mathrm{MHz})
$$

and $\eta_{3}^{\prime}(15 \mathrm{MHz})>\eta_{3}^{\prime}(25 \mathrm{MHz})$. By making use of the curves which represent eq. (3) and eq. (5), these results show that the relaxation frequency $(2 \pi \tau)^{-1}$ is far lower the frequencies used in this study. Thus a reasonable estimation of the high frequency limit $\eta_{3}^{0}-\delta \eta_{3}$ of the viscosity $\eta_{3}(\omega)$ is given by the value of $\eta_{3}^{\prime}$ at $25 \mathrm{MHz}$.
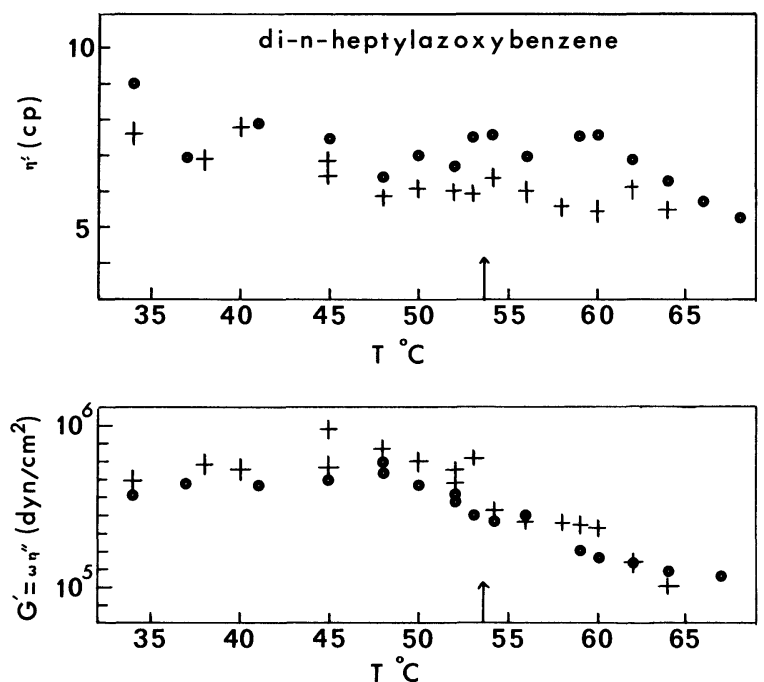

FIG. 3. - The apparent shear modulus $G^{\prime}$ and the real part $\eta_{3}^{\prime}$ of the viscosity in the nematic and smectic-A phases of di-n-heptylazoxybenzene. The symbols 9 and + are respectively for $15 \mathrm{MHz}$ and $25 \mathrm{MHz}$.

In principle the relaxation frequency $(2 \pi \tau)^{-1}$ (and the steady flow viscosity $\eta_{3}^{0}$ ) could be deduced from these measurements since it follows from eq. (3), eq. (4) and eq. (5) that :

$$
\tau^{-1}=\frac{G^{\prime}(\omega)}{\eta_{3}^{0}-\eta_{3}^{\prime}(\omega)}
$$

which leads to :

$$
\tau^{-1}=\frac{G^{\prime}\left(\omega_{2}\right)-G^{\prime}\left(\omega_{1}\right)}{\eta_{3}^{\prime}\left(\omega_{1}\right)-\eta_{3}^{\prime}\left(\omega_{2}\right)}
$$

where $\omega_{1} / 2 \pi=15 \mathrm{MHz}$ and $\omega_{2} / 2 \pi=25 \mathrm{MHz}$.

However, it is clear from figure 3 that the differences involved in formula 8 are too small compared with experimental errors to deduce a reliable value of $\tau^{-1}$. 
On the other hand, it is hopeless to use the.impedometer method to check formulae (3) and (4) directly since the available frequencies which are studied by shear wave attenuation are much higher than the relaxation frequencies which characterize liquid-crystals in the nematic-smectic A phase transition. In this case light scattering provides more useful information [15-16].

b) The nematic phase. - In a usual nematic the director follows the shear at ultrasonic frequencies [2]. Since the transition here is nearly of second order we believe that the relaxation is due to the correlated regions of size $\xi(T)$ which cannot follow the ultrasonic wave. This effect is the same as the one described by de Gennes in the isotropic phase near the transition [4].

Dioctylazoxybenzene has two mesomorphic phases, smectic A from $39^{\circ}$ to $64.6^{\circ} \mathrm{C}$ and nematic from $64.6^{\circ}$ to $66.9^{\circ} \mathrm{C}$. The nematic to smectic-A phase transition is first order. Our measurements of $R$ and $X$ at $15 \mathrm{MHz}$ are reported in figure 4 . In the smectic-A phase we observe that $R$ and $X$ are quite different, as seen previously for the diheptyl-compound. In the nematic phase, we found $R \simeq X$, as expected. Since the A-N transition is first order, the relaxation frequency $(2 \pi \tau)^{-1}$ is expected to be higher than that of the diheptyl-compound [17]. However, since the values of $G^{\prime}$ and $\eta_{3}^{\prime}$ reported in figure 5 are of the same order of magnitude as those of the diheptyl-compound, the only thing which can be said is that the relaxation frequency is below $15 \mathrm{MHz}$. Thus the value of $\eta_{3}^{\prime}$ at $15 \mathrm{MHz}$ can be reasonably considered as an estimation of the high frequency limit $\eta_{3}^{0}-\delta \eta_{3}$.

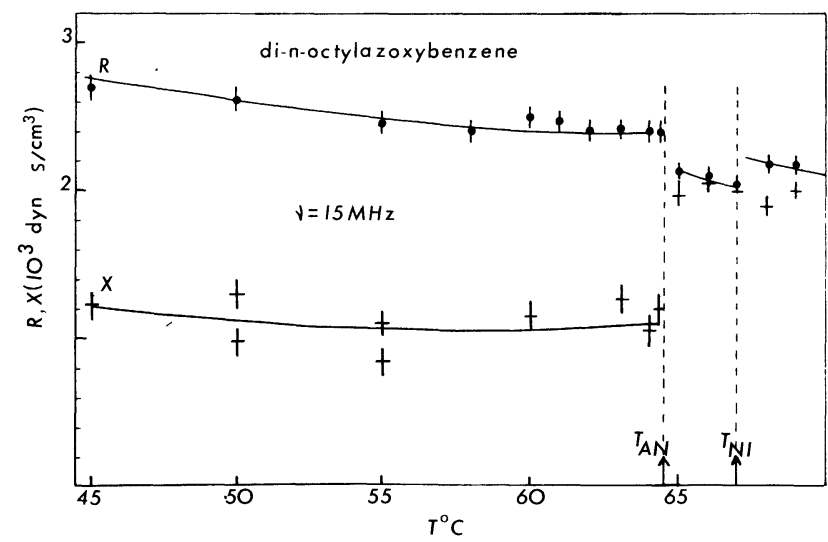

FIG. 4. - The real $R$ and imaginary $X$ parts of the shear impedance of di-n-octylazoxybenzene at $15 \mathrm{MHz}$.

We wish to conclude this letter with a remark on the ultrasonic behaviour of smectic-B phases. They are layered systems like smectic-A phases. Moreover they

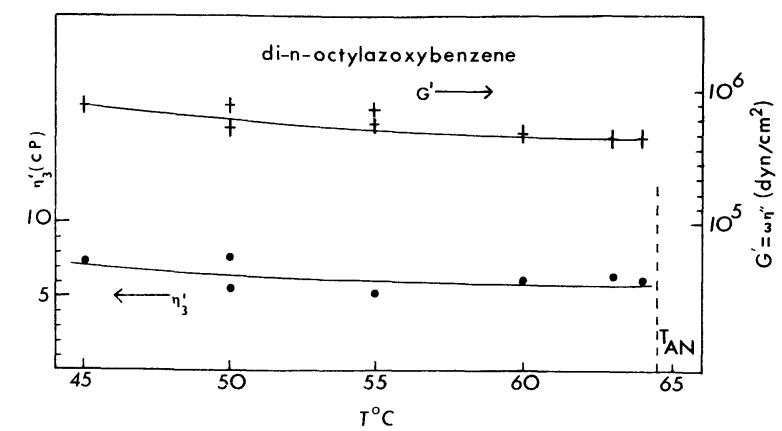

FIG. 5. - The apparent shear modulus $G^{\prime}$ and the real part $\eta_{3}^{\prime}$ of the viscosity in the smectic-A phase of di-octylazoxybenzene at $15 \mathrm{MHz}$.

present an ordering inside the layers and some correlations between the layers. As suggested by de Gennes and Sarma [18].the B phase may correspond to a three-dimensional crystal with rotational freedom or to a system of decoupled layers which might slip on each other. The shear modulus $c_{44}$ is non-zero in the first model and vanishes in the second model.

The observation of an apparent rigidity coefficient in smectic-A phases suggests, following the idea of a coupling between the shear flow and the director fluctuations, that the smectic-B phases which correspond to the second model $\left(c_{44}=0\right)$ would present in fact an apparent rigidity coefficient $G^{\prime}=c_{44} \neq 0$ at ultrasonic and at higher frequencies. This is supported by our earlier study of the smectic-B phase of N-pbutyloxybenzylidene-p-n-octylaniline (BBOA) [19] where we have observed an apparent rigidity coefficient $G^{\prime}=c_{44}$ whereas it was expected that we would observe the behaviour predicted by the second model $\left(c_{44}=0\right)$ since the interlayer correlation is weak ( $<2$ layers) [20] compared to the ultrasonic penetration depth.

An apparent rigidity coefficient $c_{44}$ has also been observed on other compounds at $110 \mathrm{MHz}$ [21] and at Brillouin frequencies [22]. The values of $G^{\prime}$ quoted in reference [21] are a hundred times higher than those found here. These high values may be caused by important correlations between layers or alternatively by director fluctuations since formulae (4) and (5) show that $G^{\prime}$ increases with the frequency. More detailed comparisons are not possible since the phases and the compounds are not the same. Moreover the director fluctuations may vary from the A to the B phase.

Acknowledgments. - We are very grateful to Dr. de Jeu and Dr. Van der Veen for kindly providing the samples of diheptyl and dioctylazoxybenzene and to $\mathrm{F}$. Brochard for valuable discussions. 


\section{References and footnotes}

[1] Moore, R. S. and McSkimin, H. J., in Physical Acoustics (Academic Press) volume 6, 1970.

See also Barlow, A. J. and Subramanian, S., Brit. J. Appl. Phys. 17 (1966) 1201.

[2] Kiry, F. and Martinoty, P., J. Physique 38 (1977) 153.

[3] Martinoty, P., Kiry, F., Nagaï, S., Candau, S., J. Physique 38 (1977) 159.

[4] De Gennes, P. G., Phys. Lett. A 30 (1969) 454 ; Mol. Cryst. and Liq. Cryst. 12 (1971) 193.

[5] A preliminary account of this work was presented as part of a talk at the First European Conference on Thermotropic Smectics and their Applications. Les Arcs, december 1975, J. Physique Colloq. 37 (1976) C3.

[6] Rapini, A., J. Physique Lett. 37 (1976) L-49.

[7] Martinoty, P. and Candau, S., Mol. Cryst. and Liq. Cryst. 4 (1971) 243.

[8] O’NeIL, H. T., Phys. Rev. 756 (1949) 928.

[9] JÄHnig, F., Brochard, F., J. Physique 35 (1974) 299.

Brochard, F., J. Physique Colloq. 37 (1976) C3-85.

[10] Martin, P. C., Parodi, O., Pershan, P. S., Phys. Rev. 6 (1972) 2401.

[11] Kim, M. G., Park, S., Cooper, Sr. M., Letcher, S. V., Mol. Cryst. Liq. Cryst. 36 (1976) 143.
[12] Langevin, D., J. Physique 37 (1976) 901.

[13] The consequence of this coupling on the shear viscosity $\eta_{3}$ has been analysed by F. Brochard near a second order A to C transition : Brochard, F., C. R. Hebd. Séan. Acad. Sci. 276 série B (1973) 87.

[14] Brochard, F., J. Physique 34 (1973) 411.

[15] Delaye, M., Keller, P., Phys. Rev. Lett., to be published.

[16] BiRECKI, H., SCHAETZING, R., Rondelez, F. and Litster, J. D., Phys. Rev. Lett. 36 (1976) 1376.

[17] An estimation of $(2 \pi \tau)^{-1}$ may be given taking $\bar{B}=6 \times 10^{7}$ CGS [23] and $\bar{B} / B_{\perp}=10$ [24]. With $\gamma \sim 1 \mathrm{p}$ it follows that $(2 \pi \tau)^{-1} \sim 1 \mathrm{MHz}$.

[18] De Gennes, P. G. and Sarma, G., Phys. Lett. 38A (1972) 219.

[19] ThIRIET, Y. and Martinoty, P., J. Physique Lett. 36 (1975) L-125.

[20] Levelut, A. M., Doucet, J., Lambert, M., J. Physique 35 (1974) 773.

[21] ÜNAl, H., BACRI, J. C., J. Physique Lett. 38 (1977) 4.

[22] Liao, Y., Clark, N. A., Pershan, P. S., Phys. Rev. Lett. (1973) 639.

[23] Clark, N. A., Phys. Rev. A 14 (1976) 1551

[24] MCMillan, W. L., Phys. Rev. A 7 (1973) 1419. 